Pacific Journal of Mathematics

ON AXIOMATIC HOMOLOGY THEORY 


\section{ON AXIOMATIC HOMOLOGY THEORY}

\section{J. MiLnoR}

A homology theory will be called additive if the homology group of any topological sum of spaces is equal to the direct sum of the homology groups of the individual spaces.

To be more precise let $H_{*}$ be a homology theory which satisfies the seven axioms of Eilenberg and Steenrod [1]. Let $\mathscr{A}$ be the admissible category on which $H_{*}$ is defined. Then we require the following.

Additivity Axiom. If $X$ is the disjoint union of open subsets $X_{\infty}$ with inclusion maps $i_{\alpha}: X_{\alpha} \rightarrow X$, all belonging to the category $\mathscr{A}$, then the homomorphisms

$$
i_{\alpha *}: H_{n}\left(X_{\alpha}\right) \rightarrow H_{n}(X)
$$

must provide an injective representation of $H_{n}(X)$ as a direct sum. ${ }^{1}$

Similarly a cohomology theory $H^{*}$ will be called additive if the homomorphisms

$$
i_{\alpha}^{*}: H^{n}(X) \rightarrow H^{n}\left(X_{\alpha}\right)
$$

provide a projective representation of $H^{n}(X)$ as a direct product.

It is easily verified that the singular homology and cohomology theories are additive. Also the Čech theories based on infinite coverings are additive. On the other hand James and Whitehead [4] have given examples of homology theories which are not additive.

Let $\mathscr{W}$ denote the category consisting of all pairs $(X, A)$ such that both $X$ and $A$ have the homotopy type of a $C W$-complex; and all continuous maps between such pairs. (Compare [5].) The main object of this note is to show that there is essentially only one additive homology theory and one additive cohomology theory, with given coefficient group, on the category $\mathscr{Y}$.

First consider a sequence $K_{1} \subset K_{2} \subset K_{3} \subset \cdots$ of $C W$-complexes with union $K$. Each $K_{i}$ should be a subcomplex of $K$. Let $H_{*}$ be an additive homology theory on the category $\mathscr{\mathscr { C }}$.

LEMmA 1. The homology group $H_{q}(K)$ is canonically isomorphic to the direct limit of the sequence

$$
H_{q}\left(K_{1}\right) \rightarrow H_{q}\left(K_{2}\right) \rightarrow H_{q}\left(K_{3}\right) \rightarrow \cdots .
$$

Received February 6, 1961.

1 This axiom has force only if there are infinitely many $X_{\alpha}$. (Compare pg. 33 of Eilenberg-Steenrod.) The corresponding assertion for pairs $\left(X_{\alpha}, A_{\alpha}\right)$ can easily be proved, making use of the given axiom, together with the "five lemma." 
The corresponding lemma for cohomology is not so easy to state. It is first necessary to define the "first derived functor" of the inverse limit functor. ${ }^{2}$ The following construction was communicated to the author by Steenrod.

Let $A_{1} \stackrel{p}{\longleftarrow} A_{2} \stackrel{p}{\longleftarrow} A_{3} \longleftarrow \cdots$ be an inverse sequence of abelian groups, briefly denoted by $\left\{A_{i}\right\}$. Let $\Pi$ denote the direct product of the groups $A_{i}$, and define $d: \Pi \rightarrow \Pi$ by

$$
d\left(a_{1}, a_{2}, \cdots\right)=\left(a_{1}-p a_{2}, a_{2}-p a_{3}, a_{3}-p a_{4}, \cdots\right) .
$$

The kernel of $d$ is called the inverse limit of the sequence $\left\{A_{i}\right\}$ and will be denoted by $\mathbb{L}\left\{A_{i}\right\}$.

Definition. The cokernel $\Pi / d \Pi$ of $d$ will be denoted by $\mathscr{L}^{\prime}\left\{A_{i}\right\}$; and $\mathfrak{Q}^{\prime}$ will be called the derived functor of $\mathbb{\Omega}$.

Now let $K_{1} \subset K_{2} \subset \cdots$ be $C W$-complexes with union $K$, and let $H^{*}$ be an additive cohomology theory on the category $\mathscr{W}$.

LEMma 2. The natural homomorphism $H^{n}(K) \rightarrow \mathfrak{Q}\left\{H^{n}\left(K_{i}\right)\right\}$ is onto, and has kernel isomorphic to $\mathbb{L}^{\prime}\left\{H^{n-1}\left(K_{i}\right)\right\}$.

REMARK. The proofs of Lemmas 1 and 2 will make no use of the dimension axiom [1 pg. 12]. This is of interest since Atiyah and others have studied "generalized cohomology theories" in which the dimension axiom is not satisfied.

Proof of Lemma 1 . Let $[0, \infty)$ denote the $C W$-complex consisting of the nonnegative real numbers, with the integer points as vertices. Let $L$ denote the $C W$-complex

$$
L=K_{1} \times[0,1] \cup K_{2} \times[1,2] \cup K_{3} \times[2,3] \cup \cdots ;
$$

contained in $K \times[0, \infty)$. The projection map $L \rightarrow K$ induces isomorphisms of homotopy groups in all dimension, and therefore is a homotopy equivalence. (See Whitehead [6, Theorem 1]. Alternatively one could show directly that $L$ is a deformation retract of $K \times[0, \infty)$.)

Let $L_{1} \subset L$ denote the union of all of the $K_{i} \times[i-1, i]$ with $i$ odd. Similarly let $L_{2}$ be the union of all $K_{i} \times[i-1, i]$ with $i$ even. The additivity axiom, together with the homotopy axiom, clearly implies that

$$
H_{*}\left(L_{1}\right) \approx H_{*}\left(K_{1}\right) \oplus H_{*}\left(K_{3}\right) \oplus H_{*}\left(K_{5}\right) \oplus \cdots
$$

with a similar assertion for $L_{2}$, and similar assertions for cohomology. On the other hand $L_{1} \cap L_{2}$ is the disjoint union of the $K_{i} \times[i]$, and

2 This derived functor has been studied in the thesis of $Z-Z$. Yeh, Princeton University 1959; and by Jan-Eric Roos [8]. 
therefore

$$
H_{*}\left(L_{1} \cup L_{2}\right) \approx H_{*}\left(K_{1}\right) \oplus H_{*}\left(K_{2}\right) \oplus H_{*}\left(K_{3}\right) \oplus \cdots .
$$

Note that the triad $\left(L ; L_{1}, L_{2}\right)$ is proper. In fact each set $K_{i} \times[i-1, i]$ used in the construction can be thickened, by adding on $K_{i-1} \times[i-3 / 2, i-1]$, without altering its homotopy type. Hence this triad $\left(L ; L_{1}, L_{2}\right)$ has a Mayer-Vietoris sequence. The homomorphism

$$
\psi: H_{*}\left(L_{1} \cap L_{2}\right) \rightarrow H_{*}\left(L_{1}\right) \oplus H_{*}\left(L_{2}\right)
$$

in this sequence is readily computed, and turns out to be:

$$
\begin{aligned}
& \psi\left(h_{1}, h_{2}, \cdots, 0,0, \cdots\right) \\
& \quad=\left(h_{1}, p h_{2}+h_{3}, p h_{4}+h_{5}, \cdots\right) \oplus\left(-p h_{1}-h_{2},-p h_{3}-h_{4}, \cdots\right) ;
\end{aligned}
$$

where $h_{i}$ denotes a generic element of $H_{*}\left(K_{i}\right)$, and $p: H_{*}\left(K_{i}\right) \rightarrow H_{*}\left(K_{i+1}\right)$ denotes the inclusion homomorphism.

It will be convenient to precede $\psi$ by the automorphism $\alpha$ of $H_{*}\left(L_{1} \cap L_{2}\right)$ which multiplies each $h_{i}$ by $(-1)^{i+1}$. After shuffling the terms on the right hand side of the formula above, we obtain

$$
\psi \alpha\left(h_{1}, h_{2}, \cdots\right)=\left(h_{1}, h_{2}-p h_{1}, h_{3}-p h_{2}, h_{4}-p h_{3}, \cdots\right) .
$$

From this expression it becomes clear that $\psi$ has kernel zero, and has cokernel isomorphic to the direct limit of the sequence $\left\{H_{*}\left(K_{i}\right)\right\}$. Now the Mayer-Vietoris sequence

$$
0 \longrightarrow H_{*}\left(L_{1} \cap L_{2}\right) \stackrel{\phi}{\longrightarrow} H_{*}\left(L_{1}\right) \oplus H_{*}\left(L_{2}\right) \longrightarrow H_{*}(L) \longrightarrow 0
$$

completes the proof of Lemma 1 .

The proof of Lemma 2 is completely analogous. The only essential difference is that the dual homomorphism

$$
H^{*}\left(L_{1} \cap L_{2}\right) \stackrel{\psi}{\longleftarrow} H^{*}\left(L_{1}\right) \oplus H^{*}\left(L_{2}\right)
$$

is not onto, in general. Its cokernel gives rise to the term $\mathbb{R}^{\prime}\left\{H^{n-1}\left(K_{i}\right)\right\}$ in Lemma 2.

Now let $K$ be a possibly infinite formal simplicial complex with subcomplex $L$, and let $|K|$ denote the underlying topological space in the weak (=fine) topology. (Compare [1 pg. 75]) Let $H_{*}$ denote an additive homology theory with coefficient group $H_{0}($ Point $)=G$.

LEMma 3. There exists a natural isomorphism between $H_{q}(|K|,|L|)$ and the formally defined homology group $\boldsymbol{H}_{q}(K, L ; G)$ of the simplicial pair.

Proof. If $K$ is a finite dimensional complex then the proof given 
on pages 76-100 of Eilenberg-Steenrod applies without essential change. Now let $K$ be infinite dimensional with $n$-skeleton $K^{n}$. It follows from this remark that the inclusion homomorphism

$$
H_{q}\left(\left|K^{n}\right|\right) \rightarrow H_{q}\left(\left|K^{n+1}\right|\right)
$$

is an isomorphism for $n>q$. Applying Lemma 1, it follows that the inclusion

$$
H_{q}\left(\left|K^{n}\right|\right) \rightarrow H_{q}(|K|)
$$

$\mathrm{i}_{\mathrm{s}}$ also an isomorphism. Therefore the inclusion

$$
H_{q}\left(\left|K^{n}\right|,\left|L^{n}\right|\right) \rightarrow H_{q}(|K|,|L|)
$$

is an isomorphism for $n>q$. Together with the first remark this completes the proof of Lemma 3 .

The corresponding lemma for cohomology groups can be proved in the same way. The extra term in Lemma 2 does not complicate the proof since $\mathbb{L}^{\prime}=0$ for an inverse sequence of isomorphisms.

Uniqueness Theorem. Let $H_{*}$ be an additive homology theory on the category $\mathscr{W}$ (see introduction) with coefficient group $G$. Then for each $(X, A)$ in $\mathscr{W}$ there is a natural isomorphism between $H_{q}(X, A)$ and the $q$ th singular homology group of $(X, A)$ with coefficients in $G$.

Proof. Let $|S X|$ denote the geometric realization of the total singular complex of $X$, as defined by Giever, $\mathrm{Hu}$, or Whitehead. (References $[2,3,7]$.) Recall that the second barycentric subdivision $S^{\prime \prime} X$ is a simplicial complex. Since $X$ has the homotopy type of a $C W$-complex, the natural projection

$$
|S X|=\left|S^{\prime \prime} X\right| \rightarrow X
$$

is a homotopy equivalence. (Compare [7, Theorem 23]). Using the five lemma it follows that the induced homomorphism

$$
H_{*}\left(\left|S^{\prime \prime} X\right|,\left|S^{\prime \prime} A\right|\right) \rightarrow H_{*}(X, A)
$$

is an isomorphism. But the first group, by Lemma 3 , is isomorphic to.

$$
\mathbf{H}_{*}\left(S^{\prime \prime} X, S^{\prime \prime} A ; G\right) \approx \mathbf{H}_{*}(S X, S A ; G),
$$

which by definition is the singular homology group of the pair $X, A$.

It is easily verified that the resulting isomorphism

$$
\mathbf{H}_{*}(S X, S A ; G) \rightarrow H_{*}(X, A)
$$

commutes with mappings and boundary homomorphisms. (Compare pp. 100-101 of [1] for precise statements.) This completes the proof of the 


\section{Uniqueness Theorem.}

The corresponding theorem for cohomology groups can be proved in the same way.

\section{REFERENCES}

1. S. Eilenberg and N. Steenrod, Foundations of algebraic topology, Princeton 1952.

2. J.B. Giever, On the equivalence of two singular homology theories, Annals of Math., 51 (1950), 178-191.

3. S. T. Hu, On the realizability of homotopy groups and their operations, Pacific J. Math., 1 (1951), 583-602.

4. I. James and J.H.C. Whitehead, Homology with zero coefficients, Quarterly J. Math., Oxford (1958), 317-320.

5. J. Milnor, On spaces having the homotopy type of a $C W$-complex, Trans. Amer. Math. Soc., 90 (1959), 272-280.

6. J. H.C. Whitehead, Combinatorial homotopy I, Bull. Amer. Math. Soc., 55 (1949), 213245.

7. J. H.C. Whitehead, A certain exact sequence, Annals of Math., 52 (1950), 51-110.

8. J. E. Roos, Sur les foncteurs dérivés de lim, Comptes Rendus Acad. des Science (Paris), 252 (1961), 3702-3704.

PRINCETON UNIVERSity 



\section{PACIFIC JOURNAL OF MATHEMATICS}

\section{EDITORS}

Ralph S. Phillips

Stanford University

Stanford, California

M. G. Arsove

University of Washington

Seattle 5, Washington
A. L. Whiteman

University of Southern Californla

Los Angeles 7, California

Lowell J. Paige

University of California

Los Angeles 24, California

\section{ASSOCIATE EDITORS}

E. F. BECKENBACH

D. DERRY

H. L. ROYDEN

E. G. STRAUS

T. M. CHERRY

M. OHTSUKA

E. SPANIER

F. WOLF

\section{SUPPORTING INSTITUTIONS}

UNIVERSITY OF BRITISH COLUMBIA

STANFORD UNIVERSITY

CALIFORNIA INSTITUTE OF TECHNOLOGY

UNIVERSITY OF CALIFORNIA

MONTANA STATE UNIVERSITY

UNIVERSITY OF TOKYO

UNIVERSITY OF UTAH

UNIVERSITY OF NEVADA

NEW MEXICO STATE UNIVERSITY

OREGON STATE UNIVERSITY

UNIVERSITY OF OREGON

OSAKA UNIVERSITY

WASHINGTON STATE UNIVERSITY

UNIVERSITY OF WASHINGTON

UNIVERSITY OF SOUTHERN CALIFORNIA

AMERICAN MATHEMATICAL SOCIETY CALIFORNIA RESEARCH CORPORATION SPACE TECHNOLOGY LABORATORIES NAVAL ORDNANCE TEST STATION 


\section{Pacific Journal of Mathematics}

\section{Vol. 12, No. $1 \quad$ January, 1962}

Jonathan L. Alperin, Groups with finitely many automorphisms $\ldots \ldots \ldots \ldots \ldots \ldots \ldots \ldots$

Martin Arthur Arkowitz, The generalized Whitehead product ................ 7

John D. Baum, Instability and asymptoticity in toplogical dynamics . . . . . . . . . . 25

William Aaron Beyer, Hausdorff dimension of level sets of some Rademacher series .... $\quad 35$

Frank Herbert Brownell, III, A note on Cook's wave-matrix theorem . . . . . . . . . . . . . 47

Gulbank D. Chakerian, An inequality for closed space curves ................. 53

Inge Futtrup Christensen, Some further extensions of a theorem of Marcinkiewicz ....... 59

Charles Vernon Coffman, Linear differential equations on cones in Banach spaces . . . . . 69

Eckford Cohen, Arithmetical notes. III. Certain equally distributed sets of integers . . . . . 77

John Irving Derr and Angus E. Taylor, Operators of meromorphic type with multiple poles

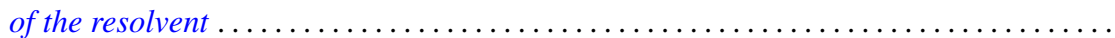

Jacob Feldman, On measurability of stochastic processes in products space .............

Robert S. Freeman, Closed extensions of the Laplace operator determined by a general class of boundary conditions, for unbounded regions ......................

Robert E. Fullerton, Geometric structure of absolute basis systems in a linear topological

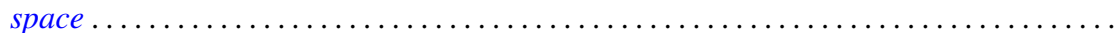

Dieter Gaier, On conformal mapping of nearly circular regions

Andrew Mattei Gleason and Hassler Whitney, The extension of linear functionals defined

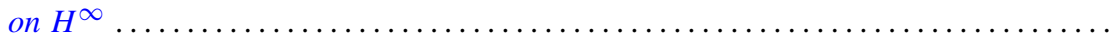

Seymour Goldberg, Closed linear operators and associated continuous linear

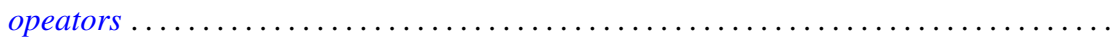

Basil Gordon, Aviezri Siegmund Fraenkel and Ernst Gabor Straus, On the determination of sets by the sets of sums of a certain order

Branko Grünbaum, The dimension of intersections of convex sets. .

Paul Daniel Hill, On the number of pure subgroups

Robert Peter Holten, Generalized Goursat problem . .

Alfred Horn, Eigenvalues of sums of Hermitian matrices ...........

Henry C. Howard, Oscillation and nonoscillation criteria for

$$
y^{\prime \prime}(x)+f(y(x)) p(x)=0
$$

Taqdir Husain, $S$-spaces and the open mapping theorem ...

Richard Eugene Isaac, Markov processes and unique stationary probability measures ...

John Rolfe Isbell, Supercomplete spaces ....................

John Rolfe Isbell, On finite-dimensional uniform spaces. II .........

N. Jacobson, A note on automorphisms of Lie algebras ..............

Antoni A. Kosinski, A theorem on families of acyclic sets and its applications

Marvin David Marcus and H. Minc, The invariance of symmetric functions of singular values...

Ralph David McWilliams, A note on weak sequential convergence.

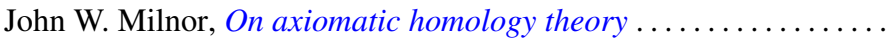

Victor Julius Mizel and Malempati Madhusudana Rao, Nonsymmetric projections in

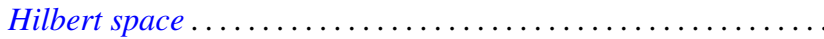

Calvin Cooper Moore, On the Frobenius reciprocity theorem for locally compact

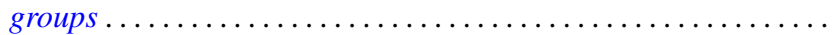

Donald J. Newman, The Gibbs phenomenon for Hausdorff means . 